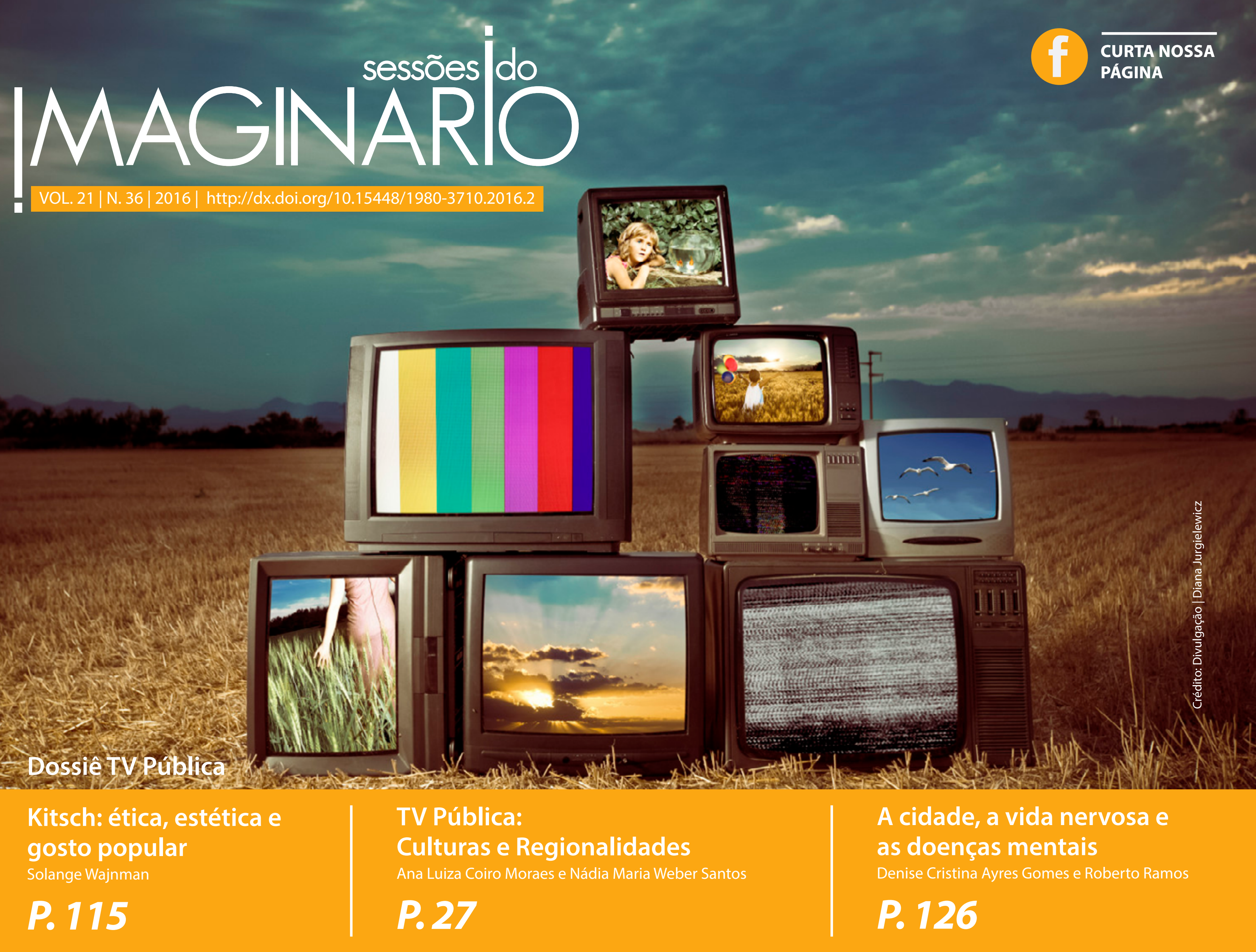




\section{Fotografias de trabalhadores de August Sander: paradigmas do século XIX para uma estética oitocentista}

Pictures of workers by August Sander: 19th century paradigms for a nineteenth-century aesthetics

Ludimilla Carvalho Wanderlei ${ }^{1}[\pi$

\section{Resumo}

Este artigo aborda as fotografias de August Sander como representação do proletariado (conceito marxista), propondo o fotógrafo como partidário de uma estética oitocentista, informada por paradigmas do século XIX, como a ideia de fotografia como reflexo da realidade, linguagem universal, arquivo e o retrato científico e/ou policial, entre outros.

\section{Palavras-chave}

August Sander; século XIX; representação; proletariado; fotografia.

\section{Abstract}

This paper is about August Sander's photographs as representation of proletariat (Marx's concept), considering that the photographer is part of a nineteenth century aesthetics, influenced by nineteenth century paradigms, such as the idea of photography as reflection of reality, universal language, archive, and scientific and/or police portrait, among others.

\section{Keywords}

August Sander; nineteenth century; representation; proletariat; photography. 


\section{Pequena história de um}

\section{fotógrafo alemão}

August Sander (1876-1964) nasceu em Herdorf (Alemanha), o quarto filho de nove irmãos. Depois de finalizar a escola primária, trabalhou em uma mina (a mineração era a principal atividade econômica da cidade) para ajudar no sustento da família. Seu primeiro equipamento fotográfico comprou com a ajuda de um tio. Na juventude, durante o serviço militar e depois dele, foi aprendiz do fotógrafo Georg Jung, na cidade de Trier. Esteve também em Berlim, Magdeburgo, Leipzig e Desdre, onde é provável que tenha frequentado como ouvinte a Academia Real de Belas Artes (Lange, 2008). O aperfeiçoamento do trabalho em estúdio e o aprendizado em pintura ${ }^{2}$ tornaram August Sander um excelente retratista. Nesse período, ele aprendeu a organizar o estúdio, controlar a luz, preparar o cenário para a foto e recepcionar os clientes. Familiarizou-se com as técnicas de revelação, cópia e retoque dos negativos, ou seja, esse foi o momento da formação básica para o apuro técnico que marca seu trabalho.

Em 1901, vai morar em Linz, onde começa como sócio de um estúdio fotográfico, que em seguida adquire, rebatizando-o de Atelier Fotográfico de Primeira Ordem August Sander. Até aquele momento, dedicase a produzir principalmente retratos encomendados para uma clientela burguesa. Em 1910, já morando em Colônia, enfrenta a concorrência de outros profissionais e faz de forma itinerante retratos de camponeses na cidade de Westerwald.

\section{Homens do século XX}

Seu projeto artístico-documental deve ter começado entre 1920 e 1925 (Lange, 2008), com sessões dividi- das de acordo com tipos humanos ${ }^{3}$. A decisão por um trabalho não-comercial é associada ao contato com o grupo Progressistas de Colônia que, na estética direta e objetiva de suas obras, transmitiam uma visão coletiva da estrutura social. Lugon (2010) também aponta uma aproximação entre esses trabalhos ${ }^{4}$ e Rostos de uma época (no original Antlitz der Zeit, 1929) - primeiro livro de Sander, um ponto de partida para Homens do século $X X$. É preciso pensar, ainda, a ligação entre esses artistas olhando para o contexto da República de Weimar:

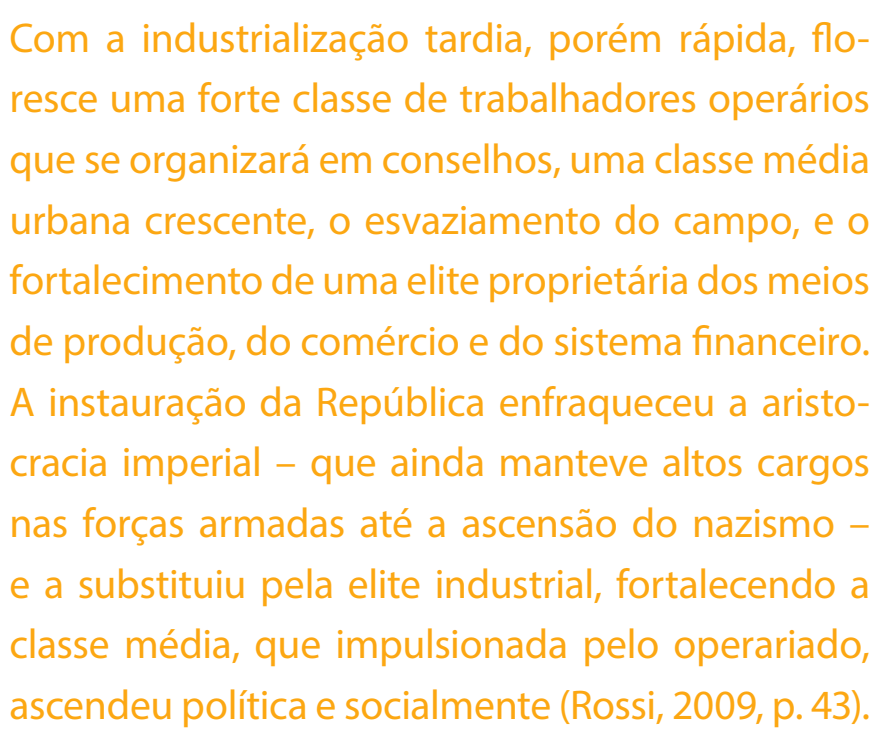
resce uma forte classe de trabalhadores operários que se organizará em conselhos, uma classe média urbana crescente, o esvaziamento do campo, e o fortalecimento de uma elite proprietária dos meios de produção, do comércio e do sistema financeiro. A instauração da República enfraqueceu a aristocracia imperial - que ainda manteve altos cargos nas forças armadas até a ascensão do nazismo e a substituiu pela elite industrial, fortalecendo a classe média, que impulsionada pelo operariado, ascendeu política e socialmente (Rossi, 2009, p. 43).

No cenário político, grupos de esquerda e de direita se opunham (Rossi, 2009, p. 43), e os Progressistas de Colônia (de esquerda) problematizavam as questões sociais geradas pela industrialização e a consequente polarização entre trabalhadores e empregadores. Embora Sander não tenha assumido uma posição política explícita, o entendimento da sociedade como estratificação de sujeitos divididos em grupos coincide com a ideia de tipologia do seu projeto Homens do século XX (Brückle, 2013). O livro está dividido em sete grupos: O camponês, $\mathrm{O}$ artesão, A mulher, Classes e profissões, Os artistas, A grande cidade e Os marginalizados ${ }^{5}$.

Homens do século $X X$ é um projeto inacabado. A própria magnitude da proposta - um estudo completo da sociedade alemã em fotos - já inviabiliza a empreitada. Mesmo assim, ainda saíram duas versões: uma em 1980 e outra em 2002. Perseguido pelos nazistas (seu livro Rostos de uma época foi proibido) e "à margem do mundo fotográfico oficial, ausente de grandes exposições e revistas" (Lugon, 2010, p. 120), seu nome só é consagrado de fato na década de 70 , quando surgem novos representantes do estilo documental na fotografia alemã e uma exposição coloca -os lado a lado em 1980 (Lugon, 2010, p. 121).

\section{Sobre o conceito de proletariado}

No que se refere às imagens de trabalhadores na obra de Sander, adotamos o conceito de proletariado (Marx, 1999 [1848]), que se refere aos indivíduos responsáveis pela força de trabalho em um sistema capitalista, ou seja, aqueles que não detêm a propriedade dos meios de produção. $O$ proletariado faz parte da estrutura de uma obra ampla, que pretendia apontar as principais esferas de uma determinada população, em uma interpretação de contexto histórico. E embora haja registro de publicações com perfil aproximado (Brückle, 2013), Homens do século $X X$ responde ao enquadramento temporal escolhido no que diz respeito às características de uma representação oitocentista, não somente no plano formal (onde encontramos a proximidade com os retratos científicos e policiais), mas também em relação a paradigmas da modernidade que vamos esclarecer a seguir. 
Paradigmas modernos e a

\section{retórica de Sander}

Homens do século XX é um trabalho artístico, pontuado por características metodológicas e formais que o aproximam do século XIX; a forma de seus retratos é herdada dos documentos fotográficos produzidos para catalogar os sujeitos desviantes de manicômios e prisões europeias. Um olhar distanciado, de um enquadramento objetificador. Escolha relacionada com a ideia de uma captura e apresentação de personagens enquanto exemplos de grupos sociais, em detrimento da individualidade de cada pessoa. Homens e mulheres reconhecidos pelo gestual, vestimenta, objetos que carregam, fisionomia, ambiente circundante. $O$ diferencial é utilizar essa construção fora dos circuitos estritos do Estado e da ciência do corpo. A capacidade de tomar essa construção como modelo para um trabalho desenvolvido em bases mais autônomas, considerando que o fotógrafo buscou dissociar o projeto de sua experiência como retratista comercial e, ainda assim, condensar questões do arquivamento, da fisionomia, entre outras.

Tudo isso nos faz crer que Homens do século XX está situado num entre-lugar: onde de um lado temos o arcabouço da documentação institucional e do outro a vacilante construção de um campo para a fotografia artística. Esse embate é típico da modernidade: a difícil demarcação de fronteiras entre ciência e arte quando se tem as próprias formas artísticas mediadas por tecnologias mecanizadas. Como produção de sentido moderno, a fotografia enfrenta o mesmo problema e seu discurso tenta ligar a separação filosófica e institucional entre ciência e práticas artísticas que caracteriza a sociedade burguesa desde o século XVIII (Sekula, 1981). Não à toa, quando se divulga o daguerreótipo, ele é apre-
Figura 1: Blast Furnace Worker (Erich Retzlaff, 1930)

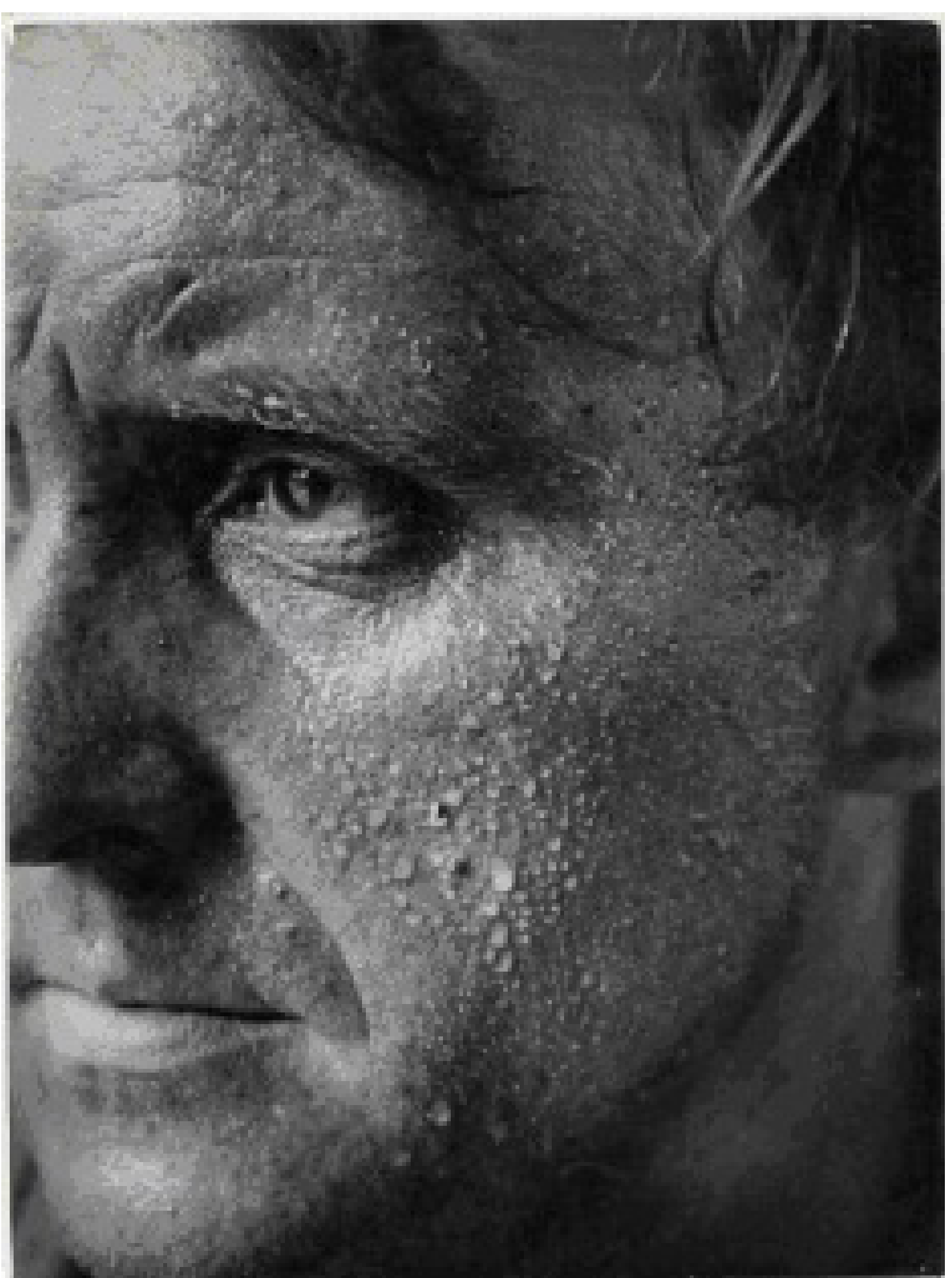

104 PORTO ALEGRE | v. 21 | n. $36 \mid 2016$ | pp. 102-114 Sessões do Imaginário 


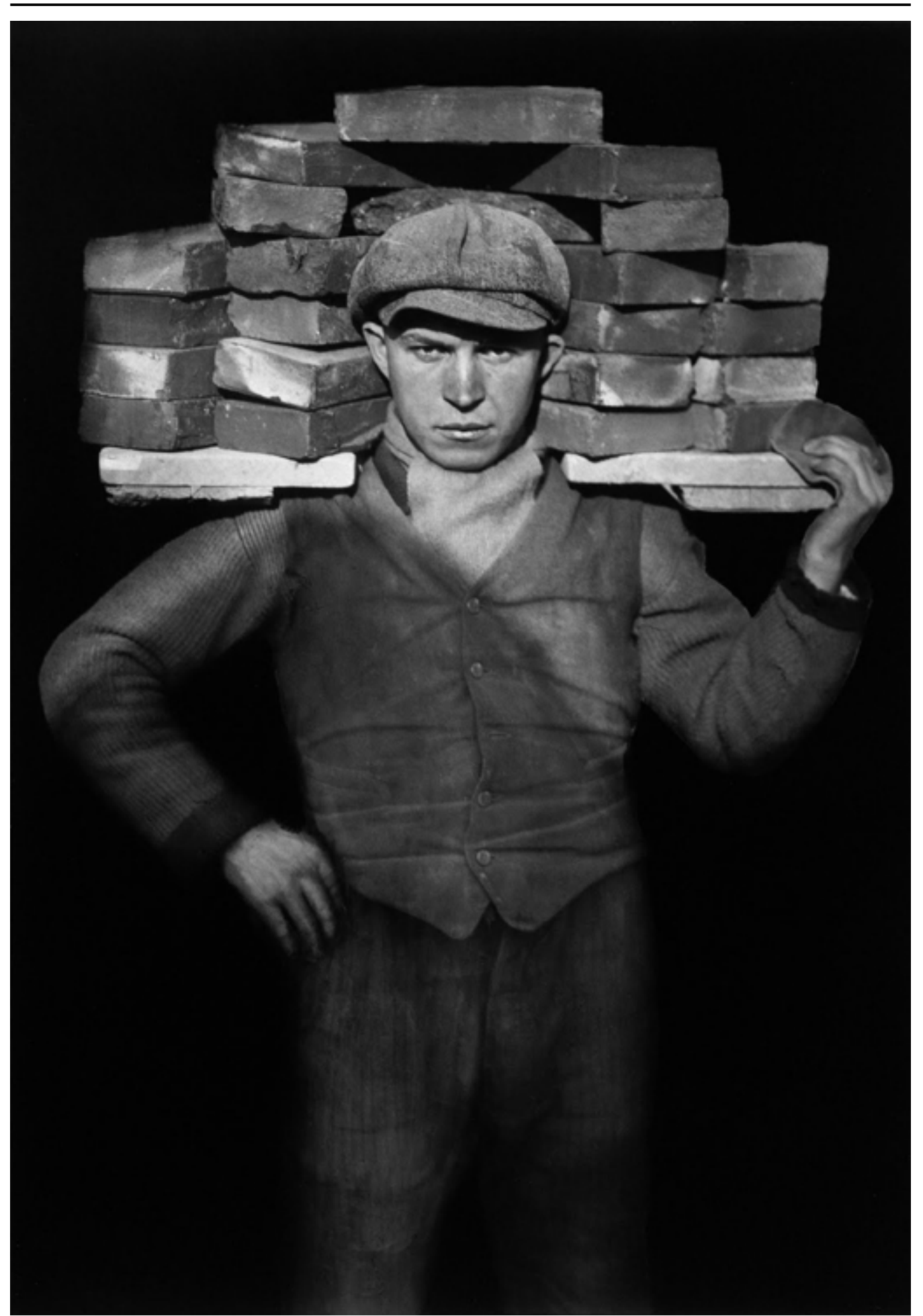

Figura 2: Pedreiro (August Sander, 1925) sentado na Academia de Ciências da França. Não à toa, o movimento pictorialista é um esforço para provar que a fotografia pode ser arte. Essas tensões caracterizam o trabalho de August Sander e por isso, ao discutir as características de suas imagens do proletariado, entenderemos o fotógrafo alemão como representante de uma estética oitocentista, pensando que a expressão pode unir a noção de estilo documental (Lugon, 2010) e alguns paradigmas da produção de sentido no século XIX que ecoam nesses retratos.

Arquivo: a captura do tempo como sintoma de uma época

Doane (2002) em seu estudo nos fala de algumas características contextuais importantes do século XIX. Ela explica que na modernidade há um desejo de apreender, capturar, controlar a passagem do tempo. Um archival impulse, do qual o cinema e a fotografia são práticas sintomáticas. Influenciadas por questões como a aceleração do modo de vida nas cidades, a circulação de informação e o ritmo determinado pelas relações de produção e consumo, as questões do registro e do arquivamento vêm resguardar aspectos da vivência incapazes de serem percebidos no curso do tempo, e que o sujeito moderno teme perder por causa disso.

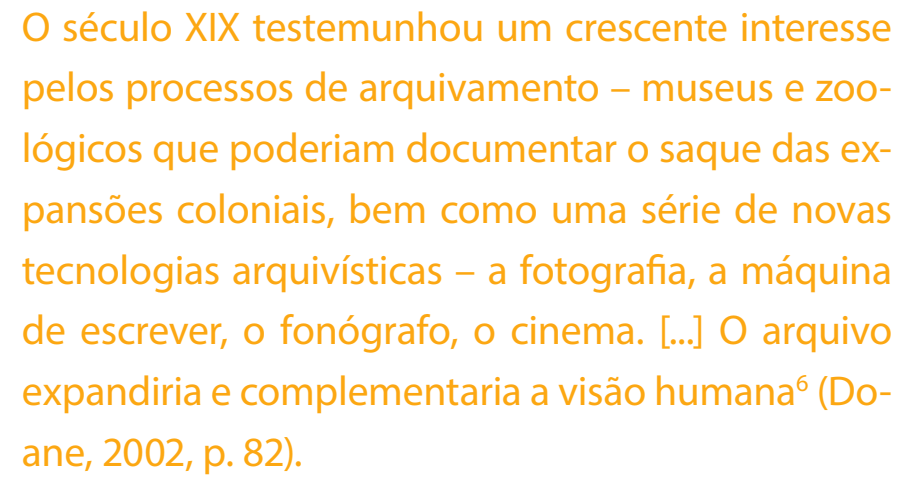


Uma vez registrado, o tempo pode ser armazenado, tornando-se assim passado (Doane, 2002, p. 23). Analogia semelhante é feita para a fotografia, cuja condição de aprisionar o tempo passado (Barthes, 1984) se apresenta logo que a captura da imagem acontece, sendo essa a relação estabelecida entre a imagem e o observador (que a contempla no presente). Nesse sentido, o momento do registro fotográfico seria uma vitória da ciência para capturar, dominar o real. Ao congelar um fragmento localizado no espaço e no tempo, a fotografia se torna um registro daquele contexto, que em um escopo mais amplo, pode ser tomado inclusive como documento histórico (Kossoy, 1989).

Outra observação interessante da autora é que o cinema entrega ao expectador um arquivo "estranhamente imaterial" - que existe no presente da projeção (Doane, 2002, p. 23). Pensando na fotografia, exatamente seu caráter de materialidade física (embora sujeita ao desgaste) é que permite o resgate, a consulta de observadores no futuro, configurando sua possibilidade de tornar-se arquivo, respondendo às preocupações com o registro do cotidiano que para Doane caracterizam a modernidade 7 . O que é aqui identificado como sintoma de uma época se confirma em uma ampla documentação praticada em diferentes instituições, constatada por John Tagg, através de diversos dados históricos:

Na década de 1860, a Ragged and Industrial School de Stockport encomendou a um fotógrafo local a elaboração de um álbum de fotos de cada um dos professores e crianças da escola. Um arquivo similar havia sido criado no Greenwich Hospital School. Na década seguinte, nos anos 1870, houve uma grande expansão do uso da documentação fotográfica. As principais prisões, por exemplo, as prisões de
Wandsworth e Millbank e a penitenciária Pentonville, criaram suas próprias oficinas fotográficas, para as quais contrataram fotógrafos fixos. As autoridades locais encomendaram pesquisas fotográficas sobre as condições de habitação e de vida em áreas da classe trabalhadora, e foram criadas empresas privadas, como a Society for Photographing Relics of Old London [Sociedade para fotografar Relíquias da Londres antiga]. Casas e lares infantis para crianças desabrigadas também seguiram o mesmo padrão de desenvolvimento, utilizando inicialmente fotógrafos retratistas locais para depois incorporar fotógrafos ao seu próprio pessoal ${ }^{8}$ (Tagg, 2005, p. 108).

Diante dessas informações, compreendemos que o papel do arquivo fotográfico é central para as ciências oitocentistas influenciando decisivamente os métodos de estudo, a coleta e armazenamento de informações. Pensando em Homens do século $X X$, compreendemos que se propõe exatamente a ser uma documentação que ficasse de legado para as gerações posteriores, oferecendo pistas sobre os indivíduos naquele momento. Uma imagem coletiva de um tempo específico. Desse ponto de vista, podemos tomá-lo como um grande projeto arquivístico. Assim também o considera Grigoriadou (2011), que comenta:

Este "ritmo repetitivo de acumulação" é aquele que serve como modelo de arquivo para construir e organizar a história fisionômica de seu tempo que pretende salvaguardar, neste caso, sob a forma de um catálogo fotográfico. Sua tentativa de construir um sistema de organização, de definir e recuperar a história, a imagem mutável do seu entorno, implica o desejo de transmitir uma série de imagens suces- sivas, a verdade do seu tempo, comunicá-la para as gerações posteriores ${ }^{10}$ (Grigoriadou, 2011, p. 306).

A produção contínua e dentro de um padrão formal de determinadas imagens, e ainda sua organização paralela, ou seja, enquanto obra, aproximam também os projetos fotográficos do ato de colecionar. Lugon (2010, p. 281) aponta as referências de Walker Evans ao seu trabalho, como o desenvolvimento de coleções ${ }^{11}$, e indica que o fotógrafo enquanto colecionador acumula e exibe aquilo que the interessa, sempre relacionando os elementos do conjunto. $O$ autor conclui que as coleções numerosas são uma característica dos projetos documentais no período entre guerras. Sobre August Sander particularmente, explica:

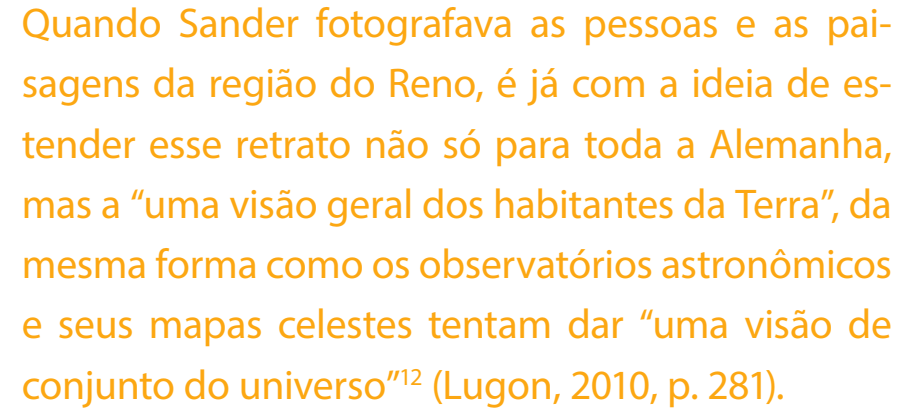

\section{Fotografia como instrumento que \\ transmite a verdade}

No contexto social do século XIX, quando o capitalismo industrial ganha força, a tecnologia constitui elemento fundamental de um discurso de progresso e desenvolvimento. Quando se fala da fotografia, é preciso estar ciente de que, como "advento", ela é resultado de experiências que envolvem disciplinas como "a ótica, a química de sais sensíveis à luz, o desenho de lentes e a engenharia de precisão de instrumentos" (Tagg, 2005, 


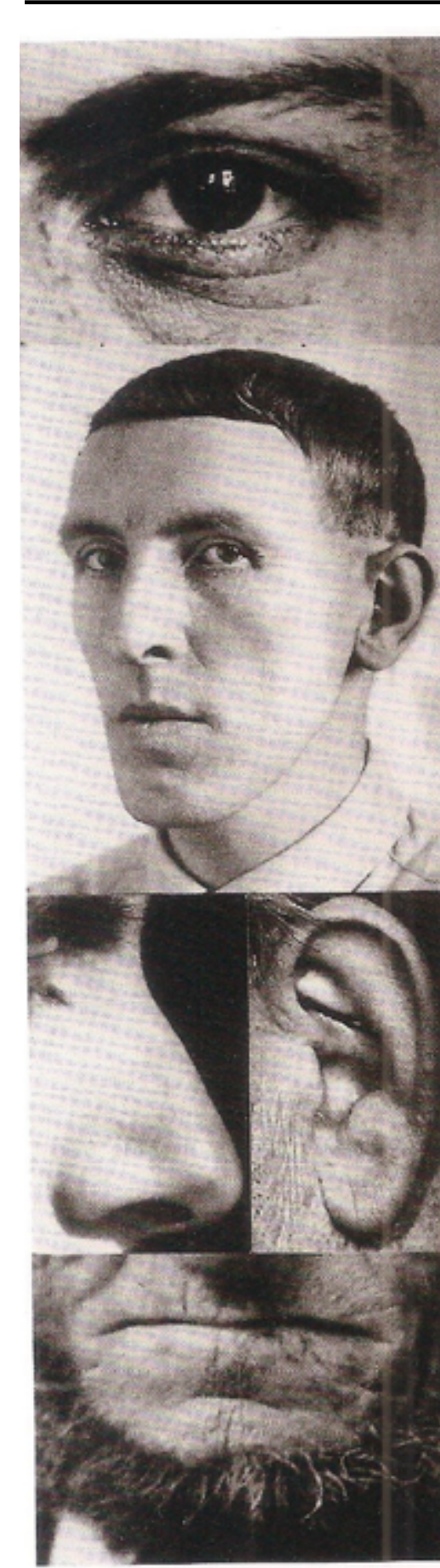

Figura 3: Estudos - Homem - colagem (August Sander, 1935) p. 58), realizadas por pesquisadores diferentes ${ }^{13}$, mas interessados em um mesmo fim: fixar uma imagem com o auxílio da luz. Surgida do acúmulo de saberes científicos, é também no colo da ciência que a fotografia vai se aninhar para ganhar reconhecimento. A ideia de "molde direto e natural da realidade" logo foi aceita, tornando-se senso comum, e não foi difícil aceitá-la como linguagem essencial para reproduzir a vida cotidiana.

Tal maneira de pensar é encontrada nas concepções de August Sander. Sekula (1981, p. 17) confirma a tendência do pensamento racionalista moderno para valorizar o conhecimento gerado pela tecnologia mecanizada, e compara os discursos sobre o daguerreótipo ao pensamento desenvolvido por Sander numa conferência que concedeu a uma emissora de rádio, cujo titulo é Photography as a universal language (1931) $)^{14}$ : "Hoje, com a fotografia, podemos comunicar nossos pensamentos, concepções e realidades a todas as pessoas na Terra; se acrescentarmos a data do ano temos o poder de fixar a história do mundo"15 (Sander apud Sekula, 1981, p. 17).

Fora a ênfase no potencial comunicativo da imagem fotográfica, o trabalho do alemão carrega o embate "ciência x arte" que - conforme dissemos - caracteriza os anos 1800. Em outro trecho da mesma conferência cita$\mathrm{da}$, Sander afirma que nenhuma linguagem é tão compreensível quanto a fotográfica, "aplicando-se tanto à cultura quanto ao mercado", dando a entender que arte e comércio são espaços diferentes (e por isso valorados socialmente de maneira distinta), mas igualmente habitados pela técnica fotográfica. Ou seja: reconhece uma fronteira separando os campos de uma fotografia utilitária e outra artística que, ao iniciar seu grande projeto, procura demarcar.

Por outro lado, as referências da fotografia policial e/ou científica transparecem nas suas imagens e nem por isso deixam de compor uma obra autoral. O dilema entre ciência e arte de fato está quase sempre presente na discussão sobre o status artístico da fotografia, tendo em vista uma relação inevitável em que o sujeito lida com uma máquina. Isso está também na base das comparações entre pintura e fotografia, onde a primeira seria mais guiada pela criatividade e a segunda, estaria sempre subordinada à "especificidade do meio". Mesmo no campo documental - conforme já abordado - discutiu-se a questão de "refletir o real sem intervenção", como se a presença de alguém por trás da câmera pudesse ser apagada.

O mérito de Homens do século XX é exatamente colocar como subtexto essa discussão, trazendo em sua própria concepção essa dicotomia, demonstrando que conciliar paradigmas tecnológicos e códigos estéticos é na verdade a condição das artes mecânicas surgidas na modernidade. A fotografia e o cinema são produtos do pensamento cientííco, mas o que os define enquanto arte são os atores que protagonizam sua criação (bem como suas intenções) e o fato de serem validados (ou não) nas instâncias legitimadoras do campo artístico (academia, mercado de arte, grupos de artistas, críticos, instituições como museus e galerias). Dito isso, não há qualquer problema em unir conceitos e referências tomados das ciências e empregá-los num projeto de arte, contanto que as escolhas feitas estejam a serviço das ideias que se deseja transmitir, e esse é o caminho escolhido por Sander. Ele usa as regras do retrato oitocentista consagrado no campo científico, pois esse formato Ihe pareceu o mais correto para a classificação de tipo social que queria dar a seus personagens, sem, contudo, abandonar o cuidado formal aprendido na rotina de estúdio, sem descuidar do apuro visual. A proximidade que estabeleceu com outros artistas, assim como 
o trânsito entre os círculos culturais que sua obra teve (debatida pela crítica, valorizada por teóricos, publicação), asseguram-lhe um lugar definitivo na história da fotografia artística.

\section{Fisionomia: leitura de corpos}

Nos anos de 1930, o lançamento de algumas obras fotográficas sobre a sociedade alemã indicam o interesse teórico pelo pensamento fisionômico e como esse poderia ser aproveitado na maneira de representar as pessoas naquela época (Brückle, 2013). Além de Rostos de uma época (August Sander, 1929) saíram os livros Everyday Heads (Köpfe des Alltags, 1931) de Helmar Lerski (1871-1956), German People (Deutsche Menschen, 1931) de Erich Retzlaff (1899-1993) e Face of the German People (Das deutsche Volksgesicht, 1932), de Erna Lendvai-Dircksen (1883-1962). Os comentários e críticas das obras utilizavam a fisionomia para destacar a tentativa dos fotógrafos de exaltar através principalmente do estudo do rosto (e de suas expressões e marcas), uma essência do povo alemão. Tendendo para uma abordagem científica, essas análises por vezes negligenciavam os aspectos formais das obras, onde o livro de Sander se afasta dos outros. Enquanto seus contemporâneos - a exemplo de Retzlaff - estavam interessados em imagens onde a face domina todo o enquadramento e a expressão é bastante valorizada, Sander parecia se focar em uma fisionomia em que as marcas do rosto são "lidas" como resultado da trajetória, posição social e profissão do sujeito (Rossi, 2009, p. 29), evitando uma interpretação mais subjetiva, presente em Blast Furnace Worker (Erich Retzlaff, 1930) (Figura 1), onde uma abordagem dramática é atingida pelo close, pelo suor no rosto e olhar determinado do homem (Brückle, 2013, p.11).

De acordo com Lugon (2010, p. 203), Sander criou uma divisão entre signos "orgânicos" e "inorgânicos" para se referir respectivamente ao corpo e elementos externos a ele (como a roupa) ${ }^{16}$, demonstrando a importância da linguagem corporal em seu trabalho. $O$ autor explica, ainda, que a fisionomia surge no século XVIII, é bastante utilizada como arcabouço teórico no século XIX, e retomada nos 1920, e possui basicamente duas correntes. Uma delas, preocupada principalmente com as marcas adquiridas pela pessoa com o passar dos anos. Rugas, linhas, manchas nos rostos podiam revelar a trajetória de vida de alguém.

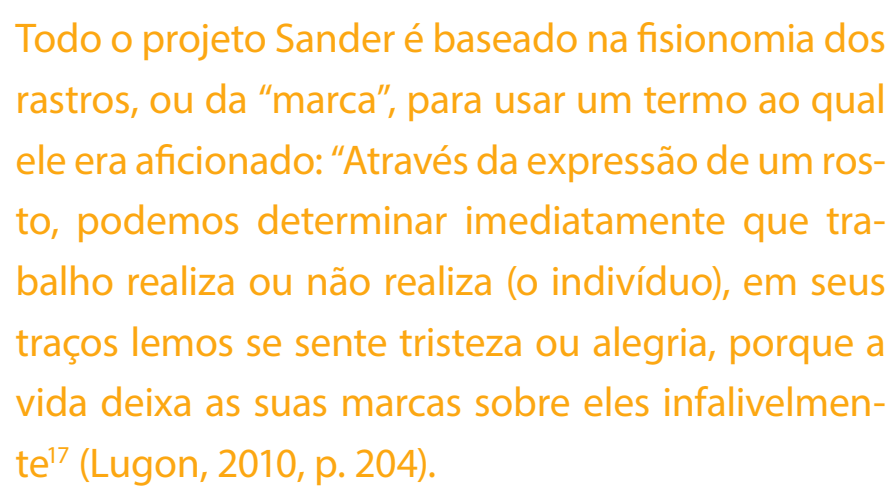

Nessa concepção de fisionomia, Sander optou por uma representação mais neutra, interessada nos aspectos inscritos na superfície dos corpos (em vez de forçar uma expressividade), ou seja, abrangendo mais do que o rosto, daí o retrato de corpo inteiro que aponta para o resgate da forma oitocentista como em "Pedreiro" (August Sander, 1925) (Figura 2) ${ }^{18}$. Aí também temos uma ideia de vestígios do tempo deixado na superfície dos corpos. Também é preciso considerar que usar a fotografia como método de estudo do corpo aproxima Sander do método de identificação de Alphonse Bertillon $^{19}$, que basicamente consistia em juntar fotos de elementos diversos do rosto (nariz, testa, boca) e do corpo (mãos), para comparar essas imagens e identificar pessoas. Alguns estudos de Sander (Figura 3) dão atenção específica às características físicas, enquadramento muito próximo ao da fotografia criminal, conforme sinalizado no quadro fisionômico de Bertillon (Figura 4). Essas imagens indicam que a identificação proposta por Sander tomava como parâmetro as mesmas referências de uma fotografia policial.

A partir dessas observações, é possível indicar que a fisionomia, bem como o estudo do corpo proposto por Bertillon, podem ser colocados em paralelo com o trabalho de August Sander, na medida em que este parece tentar compreender a população alemã evidenciando na aparência de homens e mulheres as marcas de suas trajetórias enquanto sujeitos que pertencem a diferentes classes, que têm diferentes profissões, que habitam espaços distintos (campo x cidade), de poder aquisitivo opostos.

Essa é a representação que encontramos em "Lavadeira" (August Sander, 1930) (Figura 5), uma mulher em uma condição laboral precária. As bacias no chão e as roupas empilhadas no lado direito da imagem indicam seu ganha-pão. Fora da condição de assalariada (empregada em alguma indústria ou fábrica), na organização da sociedade capitalista, restou para ela o subemprego, a desvalorização, a informalidade de um trabalho exercido na rua.

Mostrar o/a trabalhador/trabalhadora no local onde desenvolve sua atividade e junto às ferramentas e/ou utensílios relativos ao ofício é a forma mais comum utilizada por Sander. Sua visão de mundo espelha a concepção do proletariado como "parte da engrenagem capitalista", em sua complexidade, desigualdade e contradições ${ }^{20}$.

De certa forma, compreender os trabalhadores 
como força motriz de um sistema de produção é algo que remonta ao pensamento consolidado sobre o corpo no período oitocentista. Crary (2012) explica que, nesse momento, o desenvolvimento de campos da ciência como a fisiologia, por exemplo, corresponde a um ideal de que o corpo humano deveria ser entendido em suas estruturas e funcionamento, para então ser codificado e posteriormente controlado, posto em condições de produtividade, e que essa compreensão seria atingida com o auxílio da tecnologia. O autor acrescenta ainda que para além do culto à tecnologia - e de acordo com Foucault,

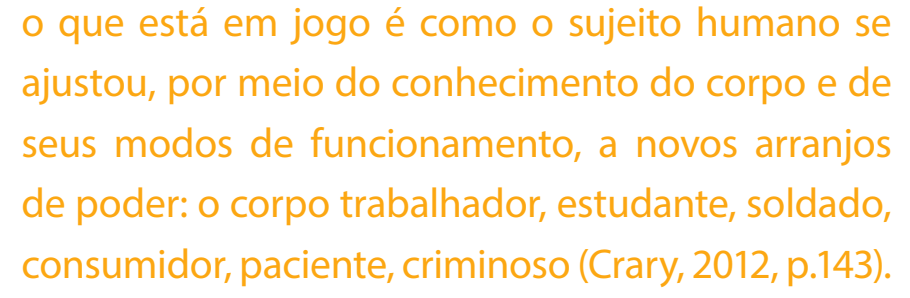

Ou seja, se toda uma sorte de aparatos mecânicos foi desenvolvida para entender a dinâmica do corpo humano e depois esse conhecimento foi colocado a serviço da industrialização da época, não é estranho que a concepção de sociedade, dos grupos e dos papeis sociais siga essa orientação. Avançando nesse ponto de vista, é compreensível que o planejamento de Sander para "catalogar" seus contemporâneos passe por recortes estritamente profissionais.

\section{Representação e retrato institucional oitocentista $x$ estilo documental}

O conceito de representação é norteado por ideias como semelhança, referente e substituição (Zunzunegui, 2010). Porém, é preciso demarcar: fotografias

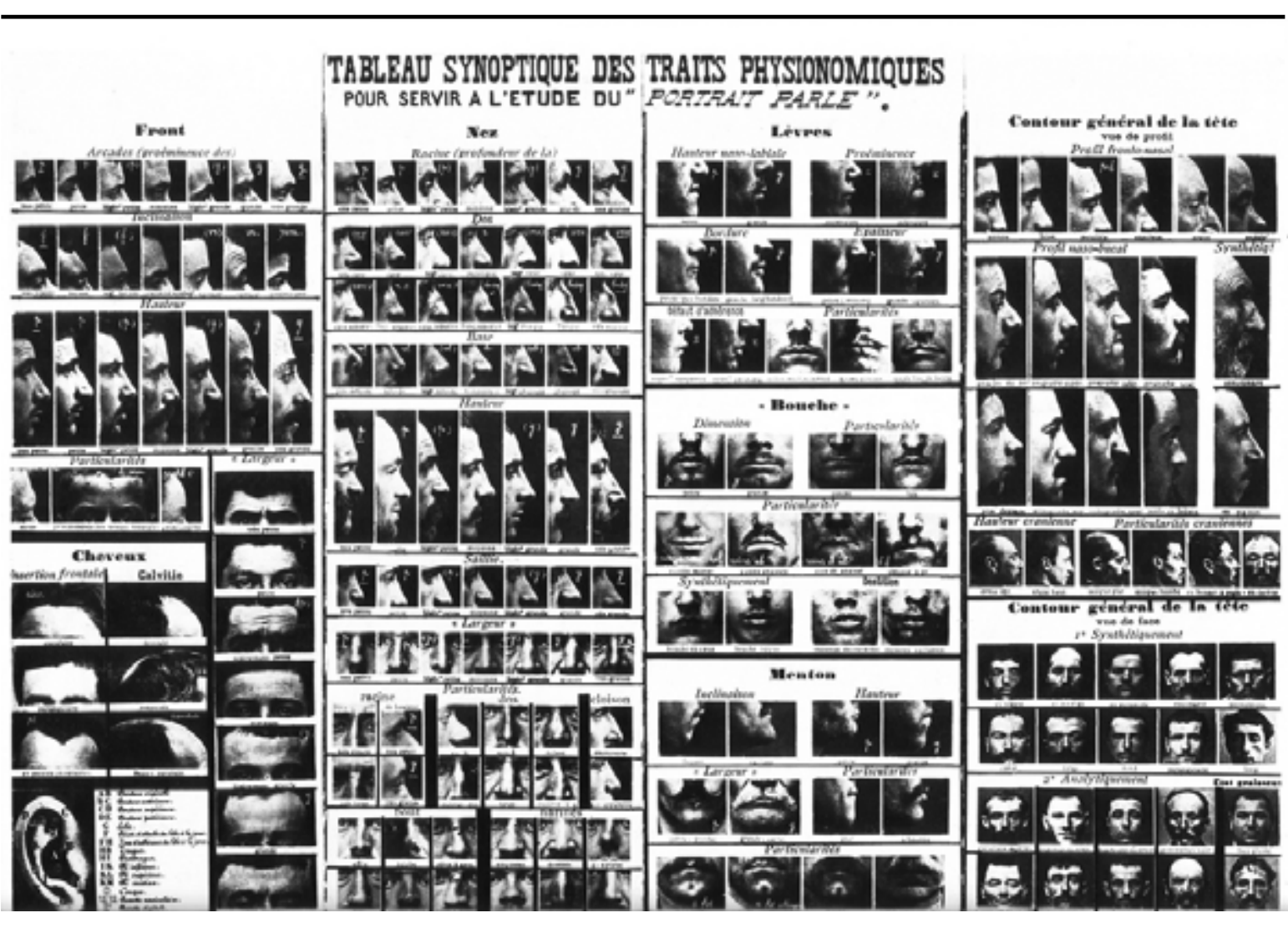

Figura 4: Bertillon poster of physical features (1893)

são imagens inscritas no campo da verossimilhança, mas não restritas a ela. Como representação, fotografias são construções, realizadas de acordo com o que o fotógrafo quer dizer. Suas escolhas, influências formais e ideologias estão presentes nas imagens. Ainda se deve considerar qual o referencial do fotógrafo para sua obra.

Alguns pontos da retórica de Sander são: frontalidade, centralização e olhar dirigido à câmera. Conforme as indicações de John Tagg (2005), um mo- delo bastante comum na fotografia do século XIX:

Na década de 1880, a visão frontal tinha se tornado o formato aceito de instantâneos populares não profissionais, mas também em documentos fotográficos como registros criminais e pesquisas sociais, nos quais este código de inferioridade social emoldurava o significado de representações de objetos de supervisão ou recuperação $0^{21}$ (Tagg, 2005, p. 53). 


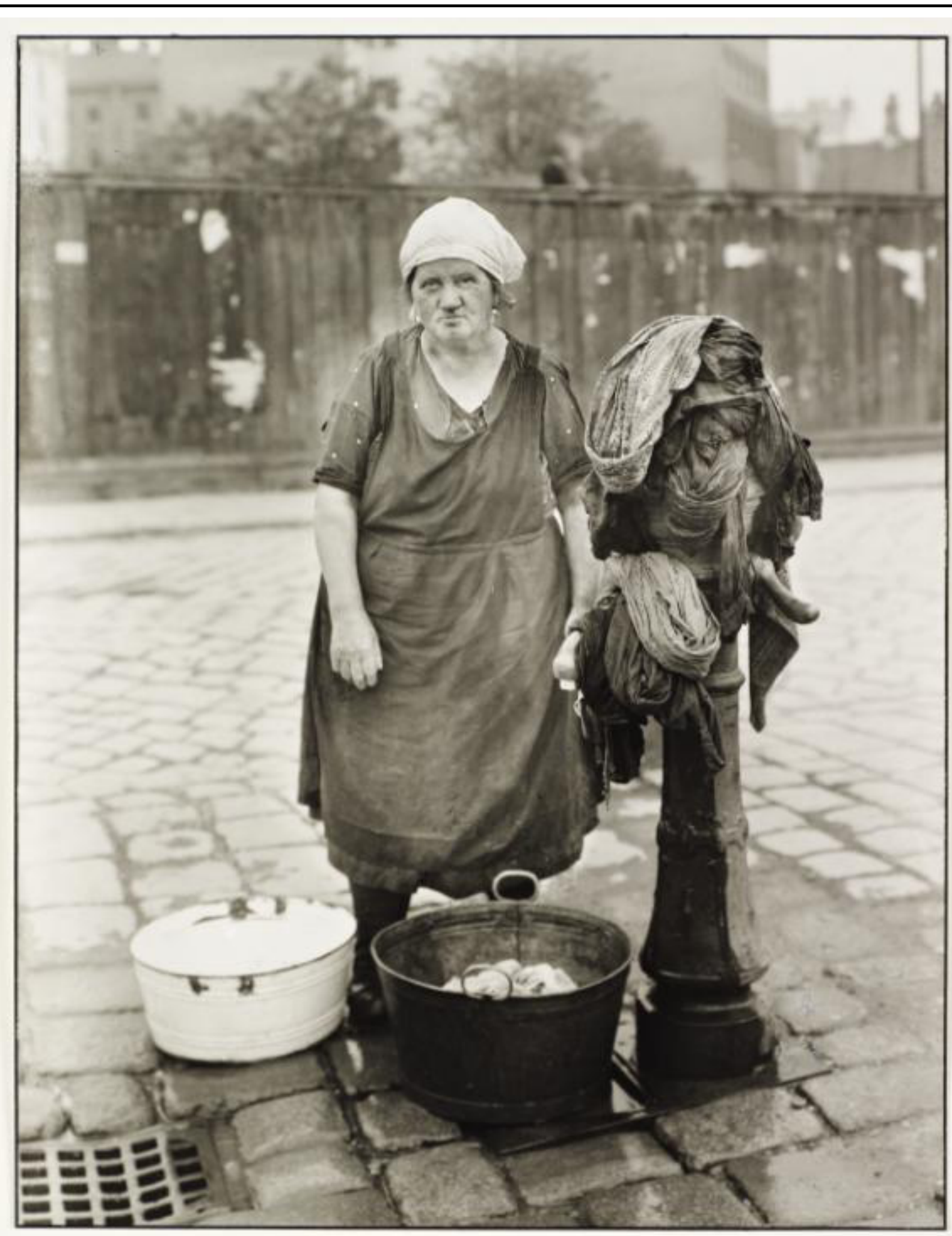

Figura 5: Lavadeira (August Sander, 1930)
Os tais objetos de supervisão eram na verdade, os cidadãos desviantes daquele período: os loucos (Figuras 6 e 7), os criminosos e suspeitos de delitos, as crianças delinquentes e até os trabalhadores, que muitas vezes moravam nos subúrbios em condições de higiene precárias. A fotografia constituiu então, um importante instrumento de registro para identificação dessas pessoas, em um sentido de vigilância. Como tal, eram produzidas sob uma série de regras que iam desde a posição do corpo em frente à câmera até a forma como a iluminação incidia no corpo do retratado ${ }^{22}$.

Uma padronização que priorizava o caráter informativo e utilitário da fotografia (não estético). Ressalte-se ainda que muitas dessas fotos foram feitas sem o consentimento de quem nelas aparece, à força mesmo. A respeito das fotos produzidas em reformatórios e pela polícia, Tagg afirma:

É um retrato do produto do método disciplinar: o corpo feito objeto: dividido e estudado; trancado em uma estrutura celular de espaço cuja arquitetura é o índice do arquivo; domesticado e forçado a entregar a sua verdade; separado e individualizado; subjugado e tornado súdito. Quando se acumulam, essas imagens vêm a ser uma nova representação da sociedade ${ }^{23}$ (Tagg, 2005, p. 101).

Se olharmos a imagem "Faxineira" (August Sander, 1928) (Figura 8) há uma correspondência entre a representação descrita acima e a fotografia em questão. A mulher é mostrada em frente a um fundo neutro e recebe uma iluminação uniforme que revela bem seu rosto, seu uniforme, sua vassoura. $O$ enquadramento é tão fechado quanto nas fotos de identificação às quais Tagg

110 PORTO ALEGRE | v. 21 | n. 36 | 2016 | pp. 102-114 Sessões do Imaginário

|MAGINARR|O 


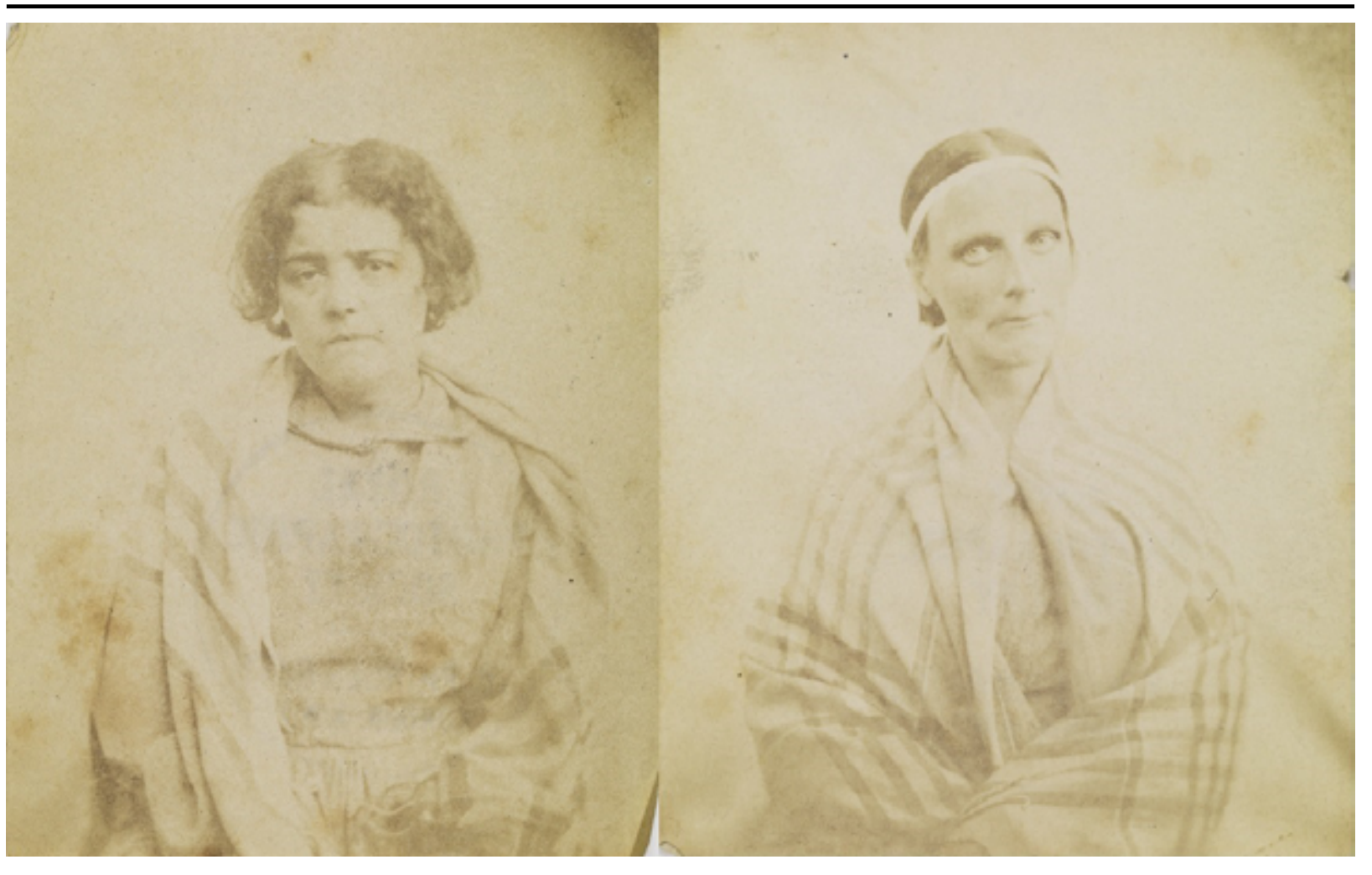

Figuras 6 e 7: Pacientes do Surrey County Asylum, Inglaterra (Hugh Welch Diamond, 1855)

(2005) se refere. Porém, a questão é que, quando fora do âmbito institucional, Sander transporta esse modelo para um projeto de contornos artísticos, e o formato é ressignificado. Ele não se aplica somente aos indivíduos marginalizados, pois a maioria dos retratos obedecem a um mesmo padrão. Trabalhadores, donos de terra, comerciantes, freiras, esportistas são vistos sob um mesmo código formal.

Considerando o "peso" de que fala o título da obra de Tagg (O peso da representação), sua reflexão nos ajuda a reconhecer a origem de uma maneira de compor vinda das fotografias científica e policial, apontando para um viés descritivo das imagens, e alertando para as questões políticas motivadoras dessa forma.

De volta a Sander, o intuito de descrever é o que se aproveita do formato, em benefício de uma clareza, de uma precisão da imagem como informação. Para Tagg (2005), produzir imagens nesse esquema é algo redutor e tem um efeito negativo, pois retira dos sujeitos o controle sobre a comunicação que podem emitir, enquanto que, para Sander, é exatamente a possibilidade de controlar a construção da fotografia - colocando todos os retratados sob as mesmas regras - que lhe permite torná-los iguais, situá-los em um mesmo nível de interpretação. Olhar para eles como um conjunto de tipos.

Atentando para as informações do estudo de Tagg (2005) sobre a representação no século XIX, percebemos que esta é fruto de um forte esquema de registro que estigmatizou por meio da fotografia uma boa parcela de indivíduos. Como imagem "oficial" produzida com intuitos científicos e objetivos definidos, o legado é tão marcante que depois de tanto tempo ainda fazemos fotos de documento seguindo os mesmos critérios. Contudo, a questão-chave é que estamos lidando com um molde aproveitado de uma maneira diferente. August Sander se apropria de um retrato bastante calculado para construir uma visão de sociedade, e não só de alguns grupos. Um olhar que procura mais uma neutralidade do que um julgamento. Assim, não é possível enxergar suas imagens em uma perspectiva tão crítica. Isso faz com que sua representação seja de uma outra ordem. Além disso, é no deslocamento dessas regras visuais para o campo artístico que se pode falar de um "estilo documental" do qual o fotógrafo alemão é partidário.

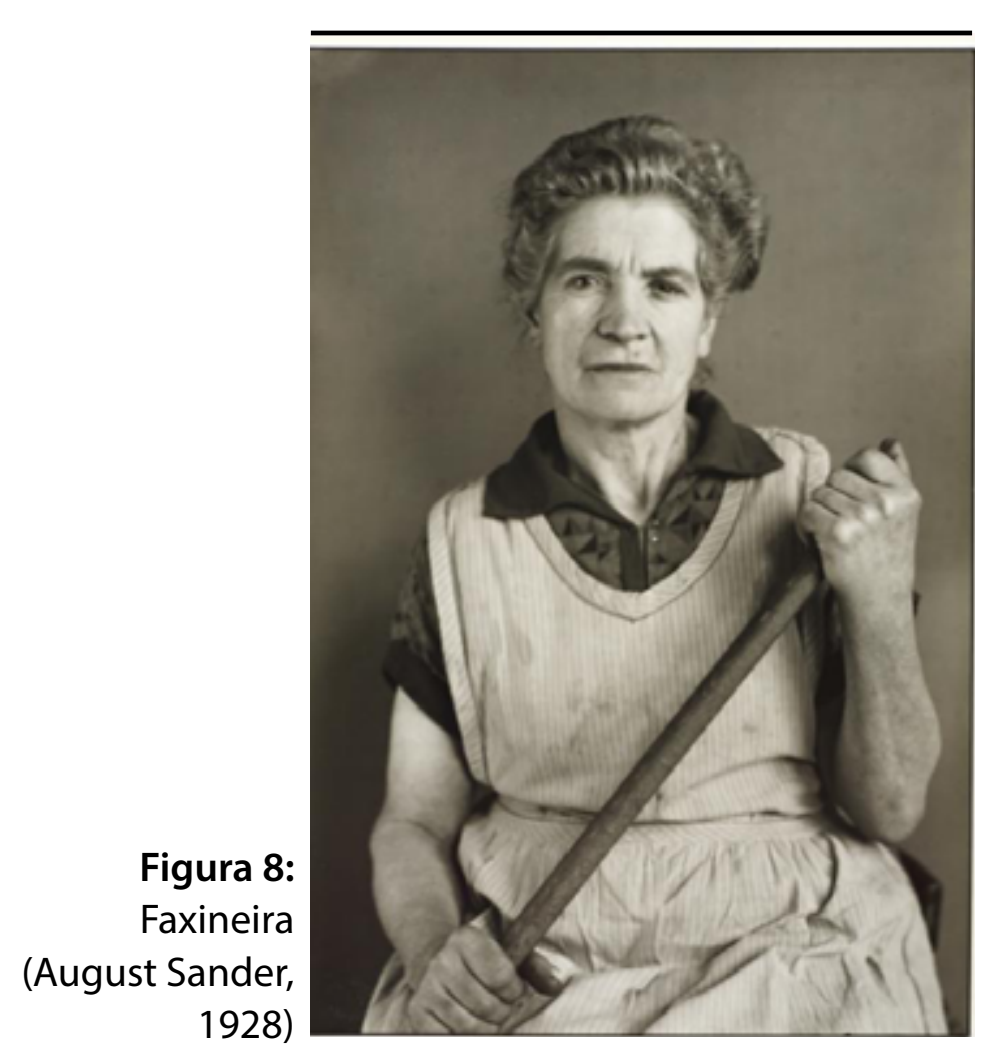


Para Olivier Lugon (2010) o "estilo documental" se caracteriza exatamente pela frontalidade, centralização do modelo, nitidez, tomada distanciada (muitas vezes enquadrando inteiramente o objeto/pessoa), e pela organização das imagens em série. $O$ estilo é uma maneira fotográfica de abordagem da realidade, muito próxima em sua forma dos retratos do século XIX citados aqui. Sander também buscava uma leitura objetiva dos tipos que fotografou em seu projeto, assim como os catálogos ou livros de registro de hospitais e delegacias se prestavam à informação sobre as pessoas que neles apareciam.

\section{Considerações finais}

Todo um conjunto de ideias, procedimentos e modelos fotográficos que podem ser apontados nos retratos de August Sander do proletariado o colocam como representante de uma estética oitocentista. Visto em um panorama sobre imagens de trabalhadores produzidas no campo da fotografia documental, seus retratos são bem semelhantes aos produzidos na esfera científica e policial nos anos 1800. Podem ser interpretados como um grande arquivo sobre a República de Weimar, montado para ser um registro iconográfico destinado ao resgate de gerações futuras e "lido" de forma direta, dada a verossimilhança do material que apresenta.

\section{Referências}

BARTHES, Roland. A câmera clara. Rio de Janeiro: Nova Fronteira, 1984.

BERGER, John. O traje e a fotografia. In: Sobre o olhar. Barcelona: Gustavo Gili Editora, 2003.

BRÜCKLE, Wolfgang. Face-off in Weimar Culture: The physiognomic paradigm, competing portrait anthologies, and August Sander's Face of Our Time. Tate Papers, n. 19, mar/2013. Disponível em: <http://www.tate. org.uk/research/publications/tate-papers/face-weimar-culture-physiognomic-paradigm-competing-portrait>. Acesso em: 27 fev. 2015.

CRARY, Jonathan. Técnicas do observador: visão e modernidade no século XIX. Rio de Janeiro: Contraponto, 2012.

DOANE, Mary Ann. Modernity, contingency, the archive: the emergence of cinematic time. Cambridge: Harvard University Press, 2002.

\section{GRIGORIADOU, Eirini. El archivo fotográfico y fisiog-} nómico de August Sander. 2011. [On-line]. Disponível em: <http://globalartarchive.com/es/investigadores-asociados/doctorado/eirini-grigoriadou/fotografia-y-archivo-en-alemania-1920-1930/>. Acesso em: 7 abr. 2015.

KOSSOY, Boris. Fotografia e história. São Paulo: Ática 1989.

LANGE, Susanne. Photo Poche: August Sander. Barcelona: Lunwerg Editores, 2008.

LUGON, Olivier. El estilo documental: De August Sander a Walker Evans 1920-1945. Salamanca: Ediciones de la Universidad de Salamanca, 2010.

MARX, Karl; ENGELS, Friedrich [1848]. 0 manifesto comunista. Rocket Edition, 1999. Disponível em: <http:// www.ebooksbrasil.org/adobeebook/manifestocomunista.pdf $>$. Acesso em: 22 fev. 2015.
ROSSI, Paulo José. August Sander e homens do século XX: uma realidade construída. 2009. Dissertação (Mestrado em Sociologia). Faculdade de Filosofia, Letras e Ciências Humanas, PUC-SP, São Paulo, 2009.

SEKULA, Allan. The traffic in photographs. Art Journal, v. 41, n. 1, 1981, p. 15-25.

https://doi.org/10.1080/00043249.1981.10792441

https://doi.org/10.2307/776511

TAGG, John. El peso de la representación: Ensayos sobre fotografías e historias. Barcelona: Gustavo Gili Editora, 2005.

ZUNZUNEGUI, Santos. Pensar la imagen. Madri: Edições Cátedra, 2010.

Notas

1 Doutoranda do Programa de Pós-graduação em Comunicação da Universidade Federal de Pernambuco - UFPE (Av. Prof. Moraes Rego, 1235, Cidade Universitária, CEP: 50.670-901, Recife/PE, Brasil).E-mail: ludimillacw@gmail.com.

2 Segundo Rossi (2009), ainda na cidade de Desdre, Sander frequentou a Academia de Artes Decorativas e costumava se apresentar como fotógrafo e pintor, inserindo no verso dos carte de visite de seu estúdio a indicação "Atelier de arte para fotografia e pintura modernas".

3 Olivier Lugon (2010, p. 74) indica que em uma carta a Erich Stenger, de julho de 1925, Sander explica que pretende realizar um recorte da sociedade da época, dividindo os retratos em ca- 
tegorias sociais e profissionais.

4 As obras em questão são Sete rostos desse tempo (1921), do pintor Franz Wilhelm Seiwert e Doze casas da época (1927), litogravuras de Gerd Arntz.

5 Tradução livre para "The Farmer", "The Skilled Tradesman", "Woman", "Classes and Professions", "The Artists", "The City", and "The Last People".

6 "The nineteenth century witnessed an upsurge of interest in archival processes - museums and zoos that could document the loot of colonial expansions as well as a series of new archival technologies - photography, the typewriter, the phonograph, cinema. (...) The archive would expand and supplement human vision" (tradução do editor).

7 Ressalte-se que aqui estamos analisando a questão do arquivo vinculada ao trabalho de Sander, no começo do século $X X$ e sua concepção de como a fotografia pode ser registro com uma certa durabilidade e importância. Dessa forma, quando falamos de materialidade, temos em mente a fotografia analógica, impressa em suporte de papel e contida em um livro, pois essa era a realidade do projeto Homens do século XX. É claro que no âmbito da fotografia digital também se podem montar arquivos, armazenados em nuvem ou em computadores pessoais, mas além de uma distinção física básica, o próprio estatuto ou destinação das imagens difere nesses casos.

8 “En los años 1860, la Ragged and Industrial School de Stockport encargó a un fotógrafo local la ela- boración de un álbum de fotos de cada uno de los profesores y niños de la escuela. Un archivo similar se había creado en la Greenwich Hospital School. En la siguiente década, los años 1870, se produjo una gran expansión del uso de la documentación fotográfica. Las principales cárceles, por ejemplo las prisiones de Wandsworth y Millbank y la penitenciaría de Pentonville, crearon sus propios talleres fotográficos, para los cuales contrataron a fotógrafos fijos. Las autoridades locales encargaron investigaciones fotográficas sobre las condiciones de vivienda y de vida en las zonas obreras, y se crearon sociedades privadas, como la Society for Photographing Relics of Old London [Sociedad para la fotografía de reliquias del antiguo Londres]. Los hogares infantiles y las residencias para niños desamparados siguieron también el mismo patrón de desarrollo, recurriendo inicialmente a fotógrafos retratistas locales para más adelante incorporar fotógrafos a su propia plantilla de personal" (tradução do editor).

9 Em um texto sobre seu projeto, Sander fala sobre a possibilidade trazida pela fotografia de transmitir aos contemporâneos e às gerações futuras a verdade de uma época (Rossi, 2009, p.82).

10 “Este 'ritmo repetitivo de acumulación' es el que le sirve como modelo de archivo para construir y organizar la historia fisiognómica de su tiempo que pretende salvaguardar, en este caso bajo la forma de un catálogo fotográfico. Su intento de construir un sistema de organización, de fijar y recuperar la historia, la imagen cambiable de su entorno, implica el deseo de transmitir en una serie de imáge- nes sucesivas, la verdad de su época, comunicarla a generaciones posteriores" (tradução do editor).

11 Em especial nos seguintes trabalhos: American Photographs (1937), Escarpate de fotos a un penique (1936), sendo que em relação a esse último, Evans se refere a ele como uma "found collection", como imagens encontradas juntas, em um álbum ou artefato semelhante. O autor ainda aponta que Evans considerava o fotógrafo um "coleccionista insensato" (Lugon, 2010, p. 279).

12 "Cuando Sander fotografía a los habitantes e los paisajes de la región renana, es ya con la ideia de ampliar este retrato no sólo a Alemania entera sino a 'una visión de conjunto de los habitantes de la Tierra' del mismo modo que los observatorios astronómicos y sus mapas celestes intentan dar 'una vista de conjunto del universo'"' (tradução do editor).

13 Embora se costume apontar Louis-Jacques-Mandé Daguerre (1787-1851) como "patrono" da fotografia, nomes como Hippolyte Bayard (1801-1887), Joseph Nicéphore Nièpce (1765-1833) e Hercule Florence (1804-1879) são relevantes na história da fotografia, pois conseguiram fixar imagens usando a luz, utilizando materiais e suportes distintos em períodos muito próximos. Daguerre conseguiu se destacar porque foi pioneiro em patentear seu invento e também devido à acolhida que teve exatamente no campo científico, o que, por sua vez, impulsionou o sucesso comercial do daguerreótipo. 
14 August Sander concedeu a uma radio alemã, em 1931, uma série de seis conferências, chamada "Essência e evolução da fotografia". A conferência citada aqui é a quinta.

15 Today with photography we can communicate our thoughts, conceptions, and realities, to all people on the earth; if we add the date of the year we have the power to fix the history of the world (...)" (tradução do editor).

16 Sobre o papel da roupa em retratos de Sander, conferir Berger, 2003, p. 35-42.

17 "Todo el proyeto de Sander se basa en esta fisiognomía de la huella, o de la "impronta", por retomar um término al que era aficionado: "A través de la expresión de um rosto, podemos determinar inmediatamente qué trabajo realiza o no realiza (el individuo), en sus rasgos leemos si siente pena o alegría, pues la vida deja sus huellas en ellos infaliblemente" (tradução do editor).

18 Rossi (2009, p.76-81) também compara imagens de Helmar Lerski e Erna Lendvai-Dircksen às de August Sander, abordando rapidamente as diferenças formais entre elas.

19 Alphonse Bertillon (1853-1914) foi um criminologista francês que criou um sistema que combinava medição de características físicas, fotografia e arquivamento, que pôde ser utilizado pela polícia para identificar criminosos reincidentes. Tradução nossa do texto disponível em: http://www.nlm. nih.gov/visibleproofs/galleries/biographies/ber- tillon.html. Acesso em: 16 fev. 2015.

20 Segundo Rossi (idem) a fotografia "Estivadores" (1929) enfatiza a questão do proletariado, ao mostrar um grupo de homens de pé, parados, dando a ideia de "braços cruzados, máquinas paradas". Ele também aponta a presença de imagens de banqueiros, industriais, em oposição clara aos trabalhadores em Homens do século XX.

21 “En los años 1880, la visión de frente se había convertido en el formato aceptado de la instantánea popular no profesional, pero también en documentos fotográficos como los antecedentes penales y las encuestas sociales, en los que este código de inferioridad social enmarcaba el significado de las representaciones de los objetos de supervisión o reforma" (tradução do editor).

22 Diversas orientações e regras sobre o uso da fotografia de identificação podem ser encontradas no estudo de John Tagg (2005) que estamos utilizando como referência aqui. Para tais informações, ver especialmente o capítulo Un medio de vigilancia: la fotografía como prueba jurídica, p.89-133.

23 "Es un retrato del producto del método disciplinario: el cuerpo hecho objeto: dividido y estudiado; encerrado en una estructura celular de espacio cuya arquitectura es el índice de archivo; domesticado y obligado a entregar su verdad; separado e individualizado; sojuzgado y convertido en súbdito. Cuando se acumulan, esas imágenes vienen a ser una nueva representación de la sociedad" (tradução do editor). 